\title{
The roles of CD82 expression in gastric cancer: a meta and bioinformatics analysis
}

\author{
Hua-Chuan Zheng ${ }^{1}$, Shuang Zhao ${ }^{1}$ and Bao-Cheng Gong ${ }^{1}$ \\ ${ }^{1}$ Department of Experimental Oncology and Animal Center, Shengjing Hospital of China Medical University, Shenyang \\ 110004, China
}

Correspondence to: Hua-Chuan Zheng, email: zheng_huachuan@hotmail.com

Keywords: CD82; gastric cancer; meta analysis; bioinformatics analysis

Received: July 04, $2017 \quad$ Accepted: July 26, $2017 \quad$ Published: October 23, 2017

Copyright: Zheng et al. This is an open-access article distributed under the terms of the Creative Commons Attribution License 3.0 (CC BY 3.0), which permits unrestricted use, distribution, and reproduction in any medium, provided the original author and source are credited.

\begin{abstract}
CD82 encodes a transmembrane glycoprotein of tetraspanins family, and functions as a tumor metastasis suppressor. We performed a systematic meta and bioinformatics analysis through multiple online databases up to March 14, 2017. We found down-regulated CD82 expression in gastric cancer, compared with normal mucosa $(p<0.05)$. CD82 expression was negatively with depth of invasion, lymph node and distant metastasis, TNM staging and dedifferentiation of gastric cancer $(p<0.05)$. A positive association between CD82 expression and favorable overall survival was found in patients with gastric cancer $(p<0.005)$. According to bioinformatics analysis, CD82 mRNA expression was higher in gastric cancer than normal tissues $(p<0.05)$. According to Kaplan-Meier plotter and TCGA database, we found that a higher CD82 expression was positively correlated with overall or progression- free survival rates of all cancer patients, even stratified by aggressive parameters or as an independent factor $(p<0.05)$. These findings indicated that CD82 expression might be employed as a potential marker to indicate gastric carcinogenesis and subsequent progression, even favorable prognosis.
\end{abstract}

\section{INTRODUCTION}

KAI1 (CD82/C33/R2/IA4) is initially identified as a tumor metastasis suppressor gene on human chromosome $11 \mathrm{p} 11.2$, and encodes a transmembrane glycoprotein of tetraspanins family (TM4SF). CD82 protein interacts with integrin $\alpha 4 \beta 1$ and other TM4SF proteins (CD4, CD8, CD19, CD21 and MHC class I and II) on cell surface to establish "the tetraspanin web" [1]. It directly binds to N-terminal region of TIMP-1 through its large extracellular loop, and facilitates membrane-bound TIMP-1 endocytosis [2]. CD82 inhibits fibronectin adhesion- induced epithelial-to-mesenchymal transition in prostate cancer cells by repressing the associated integrin signaling [3], and CD44 alternative splicing-dependent melanoma metastasis by mediating U2AF2 ubiquitination and degradation [4]. Abe et al. [5] found that CD82 strengthened E-cadherin-mediated intercellular adhesion, stabilized E-cadherin/ $\beta$-catenin complex formation, and reduced tyrosine phosphorylation of $\beta$-catenin on HGF stimulation. CD82 specifically suppressed ubiquitylation of EGFR after stimulation with heparin-binding EGF or amphiregulin [6], and attenuated compartmentalisation and ligand- induced dimerization of EGFR [7].

Risinger et al. [8] found no obvious genotypeassociated defects and histopathological abnormalities after 12 or 18 months of CD82-deficient (-/-) mice. Differentially expressed genes in mouse embryonic fibroblast of male CD82 (-/-) and wild mice were surprisingly enriched for cell division related processes. Reportedly, CD82 overexpression significantly decreased the migratory and invasive abilities of gastric cancer cells with the hypoexpression of bFGF and uPA [9]. miR-362$3 p$ expression induced the metastasis of gastric cancer cells by targeting CD82 with E-cadherin hypoexpression, $\mathrm{N}$-cadherin, and vimentin hyperexpression [10]. In the present study, we performed a meta- and bioinformatics analysis to clarify the clinicopathological and prognostic significances of CD82 expression at both mRNA and protein levels. 


\section{RESULTS}

\section{Characteristics of eligible studies}

Figure 1 is a flow diagram of paper selection for our meta-analysis. As shown in Table 1, a total of 26 articles on the relationship between CD82 expression and cancer risk, clinicopathological or prognostic parameters of gastric cancer were retrieved for our meta-analysis by immunohistochemistry in PubMed, Web of Science, BIOSIS, SciFinder and CNKI. Only 16 articles contained the samples of normal gastric mucosa [11-26]. There appeared the comparison between CD82 expression and clinicopathological characteristics of gastric cancer in 26 studies, including depth of invasion, lymph node metastasis, distant metastasis, TNM staging and Lauren's classification [9, 11-35]. Finally, the authors discussed the prognostic significance of CD82 expression in 7 articles $[9,16,18,20,26,27,34]$.

\section{Association between CD82 expression and} cancer susceptibility of gastric mucosa

We analyzed the association between CD82 expression and cancer susceptibility of gastric normal mucosa in 16 studies with 1478 cancers and 918 controls. As a result, we found down-regulated CD82 expression in gastric cancer, compared with normal mucosa (Figure 2A, $p<0.00001)$.

Association between CD82 expression and clinicopathological parameters of gastric cancer

A higher CD82 expression was detected in T0-1 than T2-4 gastric cancers (Figure 2B, $p<0.00001$ ), and in T0-2 than T3-4 ones (Figure 2C, $p<0.000001$ ). CD82 expression was negatively related to lymph node metastasis (Figure 2D, $p<0.00001$ ) and distant metastasis (Figure 2E, $p<0.01$ ) of gastric cancer. Gastric cancers with stage 0 -I or 0 -II showed CD82 overexpression, compared with ones with stage II-IV or III-IV (Figure 2F and $2 \mathrm{G}, p<0.01$ ) respectively. CD82 protein was more expressed in intestinal-type than diffuse-type carcinomas (Figure $2 \mathrm{H}, p<0.00001$ ).

\section{Association between CD82 expression and} survival rate of gastric cancer

As indicated in Figure 2I, the pooled result from 8 datasets demonstrated a positive association between

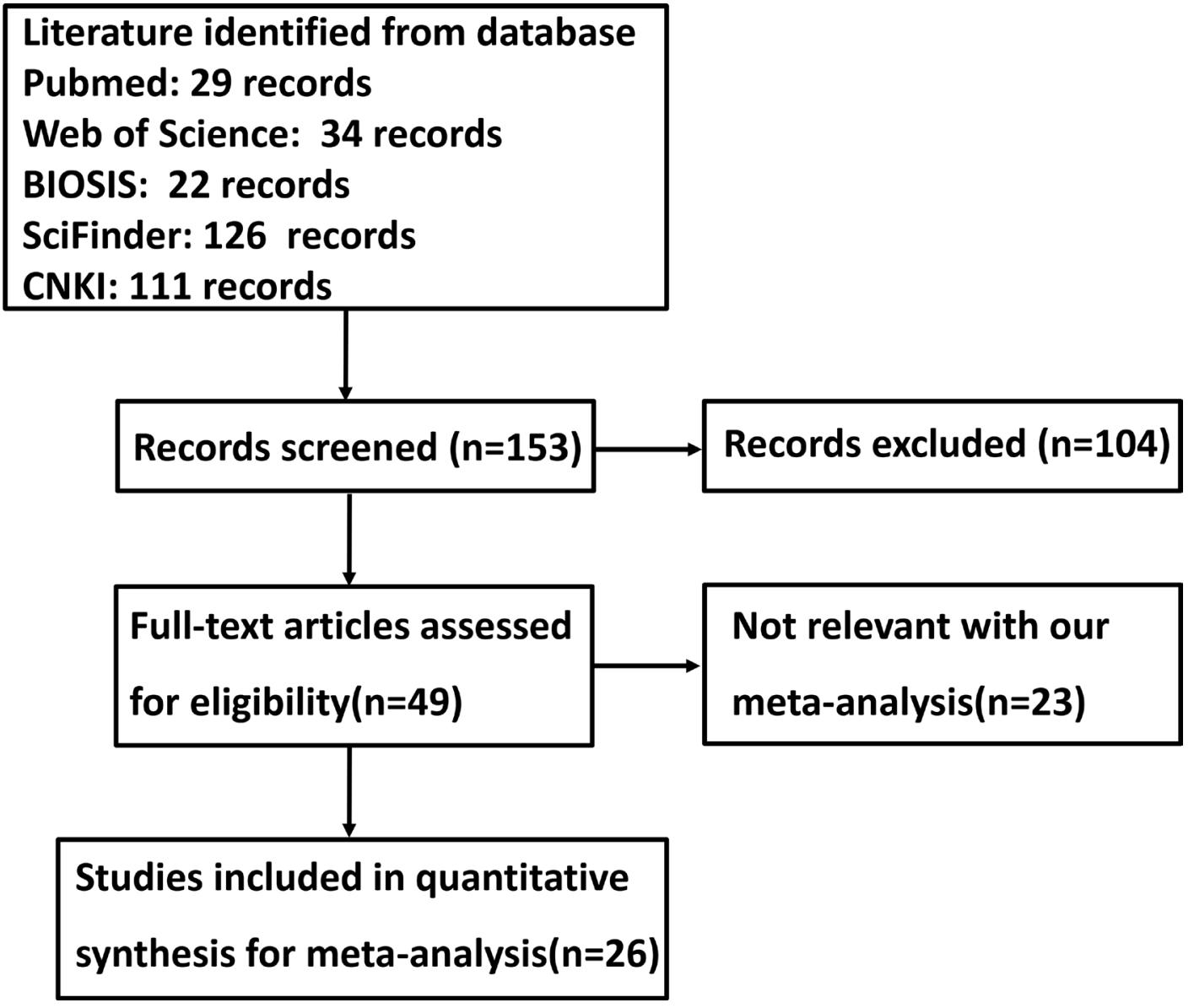

Figure 1: Flow diagram of the selection process in this meta-analysis. 
Table 1: Main characteristics of eligible studies

\begin{tabular}{|c|c|c|c|c|c|c|c|c|c|}
\hline First author & Year & Country & Ethnicity & $\mathbf{A S}$ & Cases & Control & Risk to cancer & Outcome & Quality \\
\hline Hinoda Y & 1998 & Japan & Asian & Santa Cruz & 73 & & & & 8 \\
\hline Lee HS & 2003 & Korea & Asian & Santa Cruz & 329 & & & Positive & 9 \\
\hline Zheng HC & 2004 & China & Asian & Santa Cruz & 113 & 182 & Down & & 9 \\
\hline Ilhan $\mathrm{O}$ & 2009 & Turkey & Turkish & Santa Cruz & 257 & & & & 8 \\
\hline Knoener M & 2012 & Germany & European & Santa Cruz & 271 & & & Positive & 8 \\
\hline Guo J & 2015 & China & Asian & BD Biosci & 128 & & & Positive & 8 \\
\hline $\mathrm{Lu} \mathrm{GY}$ & 2016 & China & Asian & Abcam & 325 & 325 & Down & Positive & 9 \\
\hline Wang XX & 2005 & China & Asian & Santa Cruz & 68 & 20 & Down & Positive & 9 \\
\hline Cheng HM & 2005 & China & Asian & Santa Cruz & 62 & & & Positive & 8 \\
\hline Tan L & 2005 & China & Asian & Zhongshan & 51 & & & & 8 \\
\hline Liu ML & 2006 & China & Asian & Pharmingen & 74 & 22 & Down & & 8 \\
\hline Mao SX & 2007 & China & Asian & Pharmingen & 30 & 30 & Down & & 8 \\
\hline Zhang HJ & 2007 & China & Asian & Neomarker & 71 & 20 & Down & & 8 \\
\hline Xia YB & 2007 & China & Asian & Santa Cruz & 62 & 62 & Down & & 8 \\
\hline Yin $\mathrm{K}$ & 2008 & China & Asian & Pharmingen & 75 & 75 & Down & & 8 \\
\hline Wei B & 2008 & China & Asian & Santa Cruz & 54 & 15 & Down & & 8 \\
\hline Shi YP & 2008 & China & Asian & Zymed & 92 & 10 & Down & Positive & 8 \\
\hline Zhang ZL & 2009 & China & Asian & Pharmingen & 50 & 7 & Down & & 8 \\
\hline Zhang ZJ & 2009 & China & Asian & Santa Cruz & 110 & 30 & Down & & 8 \\
\hline $\mathrm{Xu} F Y$ & 2010 & China & Asian & Santa Cruz & 65 & & & & 8 \\
\hline Ji RY & 2012 & China & Asian & Boster & 63 & & & & 8 \\
\hline Zhang XN & 2013 & China & Asian & Santa Cruz & 223 & & & & 8 \\
\hline Zhou L & 2014 & China & Asian & Maxim & 145 & 50 & Down & Positive & 8 \\
\hline Qi Q & 2014 & China & Asian & Santa Cruz & 96 & 20 & Down & & 8 \\
\hline Wang W & 2014 & China & Asian & Santa Cruz & 61 & 20 & Down & & 8 \\
\hline Kang LX & 2015 & China & Asian & Changdao & 52 & 30 & Down & & 8 \\
\hline
\end{tabular}

AS, antibody source; Down, down-regulated expression.

CD82expression and favorable overall survival in patients with gastric cancer $(\mathrm{HR}=1.76,95 \% \mathrm{CI}: 1.37-2.25$, $p<0.00001)$.

\section{Publication bias}

The heterogeneity test was performed as shown in Figure 3. Sensitivity analysis was used to evaluate individual study's influence on the pooled results by deleting one single study each time from pooled analysis. As a result, the correlation between CD82 expression and distant metastasis in Knoener's study had a significant effect on the pooled OR. When this study was excluded, the heterogeneity test was significantly reduced (data not shown).

\section{The clinicopathological and prognostic significances of $C D 82 \mathrm{mRNA}$ expression in gastric cancer}

Then, we used Cho's, Cui's, DErrico's and Wang's datasets to perform bioinformatics analysis and found that $C D 82$ mRNA expression was lower in gastric cancer than normal tissues, even stratified into intestinal-, diffuse- and mixed-type carcinomas (Figure 4A, $p<$ $0.05)$. According to Kaplan-Meier plotter, we found that a higher CD82 mRNA expression was positively correlated with overall and progression-free survival rates of all cancer patients (Figure 4B, $p<0.05$ ). As shown in Table 2, the overall and progression-free survival rates of the female or male patients, the patients receiving surgery alone, the patients with stage II or III, $\mathrm{T} 2$ or T3, N0, N1-3, N1, N3, M0, intestinal-type, diffusetype, Her2-positive or Her2-negative cancers were higher in the group of high $C D 82$ mRNA expression than that of its low expression $(p<0.05)$. According to TCGA's database, univariate analysis showed a positive link between $C D 82$ mRNA expression and the overall better prognosis of the patients with gastric cancer (Figure 4C, $p<0.05$ ). Multivariate analysis using Cox's hazard proportional model indicated that $C D 82 \mathrm{mRNA}$ expression was an independent prognostic factor for gastric cancer (Table 3, $p<0.05$ ). 
A

Normal Cancer Odds Ratio

Odds Ratio

Study or Subgroup Events Total Events Total Weight M-H. Random. 95\% C

$\begin{array}{lllllll}\text { Kang LX (2015) } & 26 & 30 & 28 & 52 & 7.6 \% & 5.57[1.70,18.23]\end{array}$

Liu ML (2006)

Lu GY (2016)

Mao SX (2007)

Qi Q (2014)

Shi YP (2008)

Wang W (2014)

Wang XX (2005)

Wei B (2008)

Xia YB (2007)

Yin $\mathrm{K}(2008)$

Zhang HJ (2007)

Zhang ZJ (2009)

Zhang ZL (2009)

Zheng HC (2004)

Zhou L (2014)

$\begin{array}{rr}26 & 30 \\ 18 & 22 \\ 300 & 325\end{array}$

$32 \quad 74 \quad 7.6 \%$

$5.91[1.82,19.16]$

$5.91[1.82,19.16]$

$17.10[10.76,27.20]$

$56.00[10.33,303.68]$

$14.35[3.15,65.46]$

$5.44[1.09,27.02]$

21.50 [4.51, 102.42]

$52.78[6.58,423.22]$

$56.44[3.20,995.20]$

$7.43[2.05,26.92]$

$68.31[9.02,517.24]$

$15.58[3.34,72.56]$

$46.95[6.17,357.59]$

$51.52[2.73,971.73]$

$3.85[2.30,6.45]$

$19.38[6.61,56.82]$

Total $(95 \% \mathrm{Cl})$

Total events

Heterogeneity: $\mathrm{Tau}^{2}=0.54 ; \mathrm{Chi}^{2}=39.06, \mathrm{df}=15(\mathrm{P}=0.0006) ; \mathrm{I}^{2}=62 \%$

$14.27[8.53,23.89]$

Test for overall effect: $Z=10.12(P<0.00001)$

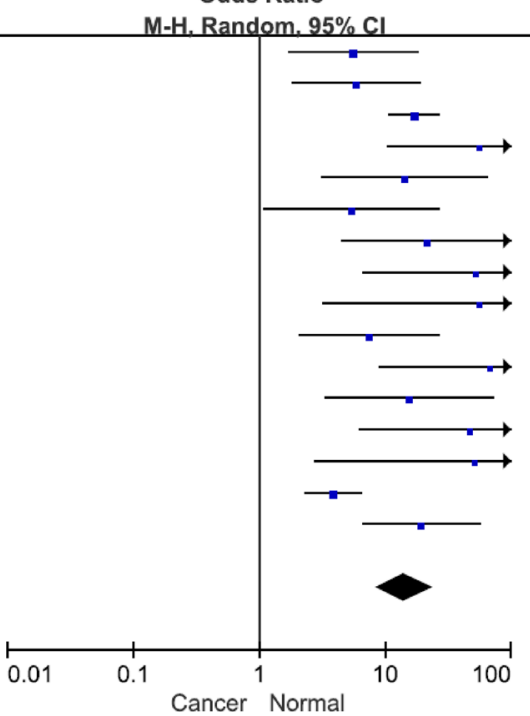

B

Study or Subgroup Events Total Events Total Weight M-H.Fixed. 95\% C

$\begin{array}{lllllll}\text { Guo J (2015) } & 12 & 16 & 16 & 112 & 2.6 \% & 18.00[5.16,62.78]\end{array}$

Ilhan $\mathrm{O}(2009)$

Kang LX (2015)

Knoener M (2012)

Liu ML (2006)

Lu GY (2016)

Shi YP (2008)

Wang XX (2005)

Xu FY (2010)

Zhang ZJ (2009)

Zhang ZL (2009)

Zheng HC (2004)

Zhou L (2014)

$\begin{array}{rrrrrr}5 & 7 & 81 & 250 & 3.2 \% & 5.22[0.99,27.46]\end{array}$

$\begin{array}{llllll}7 & 10 & 21 & 42 & 6.2 \% & 2.33[0.53,10.27]\end{array}$

$\begin{array}{llllll}28 & 34 & 140 & 237 & 15.8 \% & 3.23\end{array}[1.29,8.10]$

$\begin{array}{lllllll}15 & 25 & 17 & 49 & 11.7 \% & 2.82[1.05,7.62]\end{array}$

$\begin{array}{llllll}12 & 21 & 182 & 364 & 21.7 \% & 1.33[0.55,3.24]\end{array}$

$\begin{array}{llllll}6 & 8 & 33 & 84 & 3.7 \% & 4.64[0.88,24.36]\end{array}$

$\begin{array}{llllll}4 & 6 & 14 & 62 & 2.1 \% & 6.86[1.13,41.43]\end{array}$

$\begin{array}{llllll}9 & 20 & 14 & 45 & 12.1 \% & 1.81[0.61,5.35]\end{array}$

$\begin{array}{llllll}17 & 21 & 25 & 89 & 4.6 \% & 10.88[3.33,35.52]\end{array}$

$\begin{array}{llllll}6 & 12 & 5 & 38 & 3.1 \% & 6.60[1.52,28.75]\end{array}$

$\begin{array}{llllll}20 & 26 & 46 & 87 & 12.5 \% & 2.97[1.09,8.11]\end{array}$

Total $(95 \% \mathrm{Cl})$

215

$\begin{array}{rrrr}45 & 136 & 0.8 \% & 38.21[2.18,671.17]\end{array}$

Total events

150

$1595 \quad 100.0 \%$

$3.81[2.75,5.30]$ 639

Heterogeneity: $\mathrm{Chi}^{2}=20.88, \mathrm{df}=12(\mathrm{P}=0.05) ; \mathbf{I}^{2}=43 \%$

Test for overall effect: $Z=8.00(P<0.00001)$

C

T0-T2 T3-T4

0.01

. Fixed. $95 \% \mathrm{Cl}$

Odds Ratio

Study or Subgroup Events Total Events Total Weight M-H, Random, 95\% Cl

Guo J (2015)

Ilhan $\mathrm{O}(2009)$

Ji RY (2012)

Knoener M (2012)

Liu ML (2006)

Qi Q (2014)

Shi YP (2008)

Tan L (2005)

Wang W (2014)

Wang XX (2005)

Wei B (2008)

Xia YB (2007)

Xu FY (2010)

Yin K (2008)

Zhang HJ (2007)

Zhang XN (2013)

Zhang ZJ (2009)

Zhang ZL (2009)

Zheng HC (2004)

Zhou L (2014)

$\begin{array}{rr}22 & 64 \\ 18 & 23 \\ 6 & 10 \\ 108 & 161\end{array}$

5.06 [1.89, 13.58]

$8.79[3.14,24.62]$

$2.68[0.67,10.71]$

$1.70[1.03,2.80]$

$3.94[1.35,11.54]$

$3.20[1.36,7.54]$

$4.24[1.76,10.22]$

$3.33[1.00,11.12]$

57.48 [3.06, 1080.81]

$3.88[1.24,12.16]$

$2.91[0.85,9.96]$

$4.55[0.93,22.41]$

$2.70[0.84,8.65]$

$17.60[4.58,67.65]$

$3.50[1.24,9.92]$

$2.10[1.00,4.41]$

$5.92[2.45,14.35]$

$5.82[1.11,30.56]$

$1.33[0.63,2.82]$

$12.03[5.38,26.91]$

Total $(95 \% \mathrm{CI})$

Total events 432

$3.95[2.83,5.51]$

$=19(P=0.003) ;\left.\right|^{2}=53 \%$

Test for overall effect: $Z=8.06(P<0.00001)$

Odds Ratio

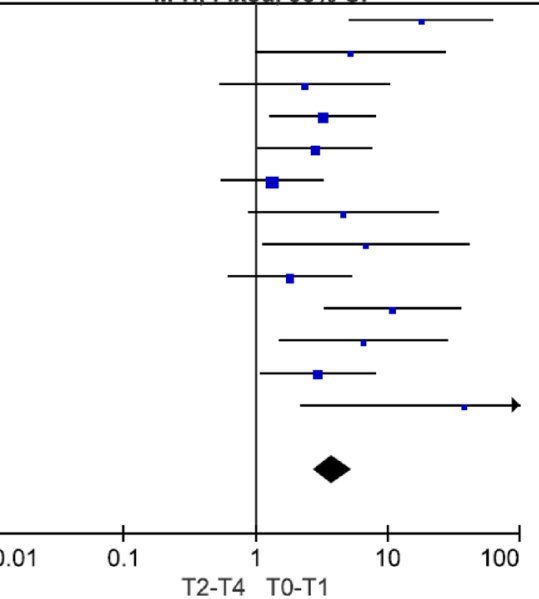

M-H, Random. $95 \% \mathrm{Cl}$


D

LN-

$\mathrm{LN+}$

Odds Ratio

Odds Ratio

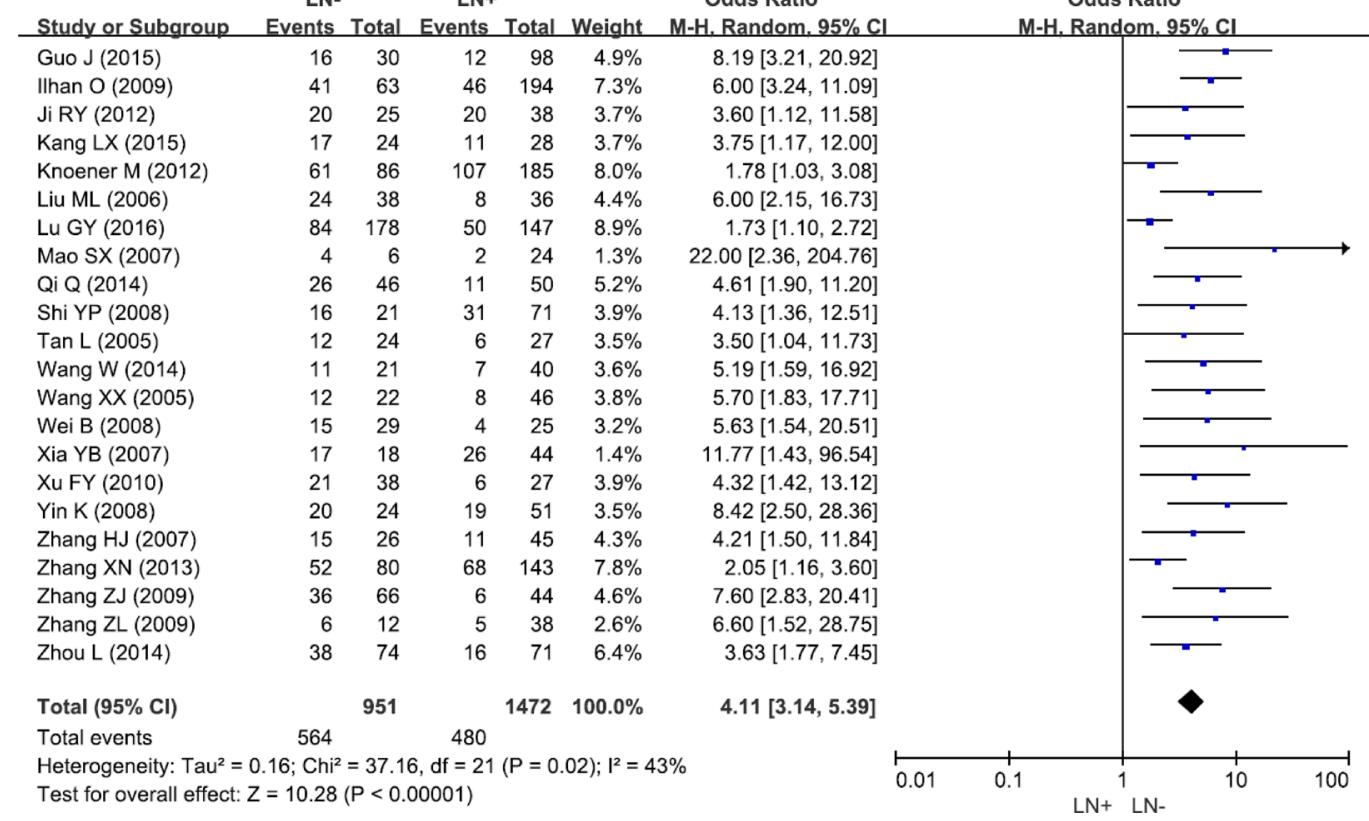

E

$\begin{array}{ccc}\text { DM- } & \text { DM+ } & \text { Odds Ratio } \\ \text { Study or Subgroup } & \text { Events } & \text { Total } \\ \text { Events } & \text { Total Weight } & \text { M-H. Fixed. 95\% Cl }\end{array}$

Odds Ratio $\begin{array}{llllllll}\text { Guo J (2015) } & 28 & 116 & 0 & 12 & 4.3 \% & 8.05[0.46,140.31]\end{array}$ $\begin{array}{lllllll}\text { Ilhan O (2009) } & 86 & 251 & 0 & 6 & 4.0 \% & 6.79[0.38,122.03]\end{array}$ $\begin{array}{lrrrrrr}\text { Knoener M (2012) } & 150 & 243 & 18 & 28 & 77.9 \% & 0.90[0.40,2.02]\end{array}$

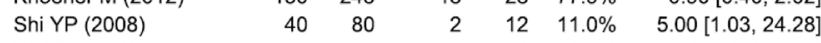
$\begin{array}{lllllll}\text { Wei B (2008) } & 19 & 43 & 0 & 11 & 2.8 \% & 18.31[1.01,330.45]\end{array}$

$\begin{array}{lllll}\text { Total }(95 \% \mathrm{Cl}) & 733 & 69 & 100.0 \% & 2.37[1.33,4.23]\end{array}$ Total events $\quad 323 \quad 20$

Heterogeneity: $\mathrm{Chi}^{2}=9.46, \mathrm{df}=4(\mathrm{P}=0.05) ; \mathrm{l}^{2}=58 \%$

Test for overall effect: $Z=2.92(P=0.003)$

Odds Ratio

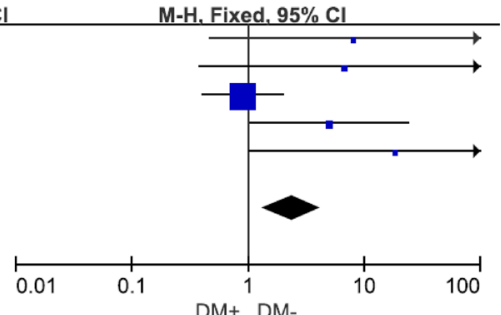

Stage 0-I Stage II-IV Odds Ratio

Study or Subgroup Events Total Events Total Weight M-H. Random. $95 \% \mathrm{Cl}$ $\begin{array}{lllllll}\text { Guo J (2015) } & 14 & 32 & 14 & 96 & 20.7 \% & 4.56[1.85,11.20\end{array}$ $\begin{array}{llllllll}\text { Illhan O (2009) } & 15 & 19 & 71 & 238 & 17.5 \% & 8.82[2.83,27.51]\end{array}$ $\begin{array}{lllllll}\text { Knoener M (2012) } & 54 & 75 & 114 & 196 & 25.3 \% & 1.85[1.04,3.30]\end{array}$ $\begin{array}{lllrrrr}\text { Zhang ZL (2009) } & 6 & 12 & 5 & 38 & 13.6 \% & 6.60[1.52,28.75\end{array}$ $\begin{array}{lllllll}\text { Zheng HC (2004) } & 24 & 46 & 33 & 67 & 22.9 \% & 1.12[0.53,2.38]\end{array}$

$\begin{array}{lllll}\text { Total }(95 \% \mathrm{Cl}) & 184 & 635 & 100.0 \% & 3.11[1.49,6.50]\end{array}$

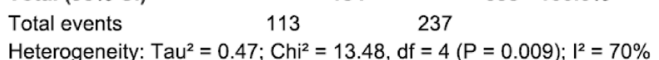

Test for overall effect: $Z=3.02(P=0.003)$

G

Stage 0-II Stage III-IV

Odds Ratio

Study or Subgroup Events Total Events Total Weight M-H. Random. 95\% C $\begin{array}{llllll}2005) & 5 & 11 & 1 & 19 & 2.7 \%\end{array}$

Guo J (2015)

Ilhan $\mathrm{O}(2009)$

Knoener M (2012)

Lu GY (2016)

Mao SX (2007)

Qi $Q$ (2014)

Wang W (2014)

Wang XX (2005)

Wei B (2008)

Xia YB (2007)

Yin K (2008)

Zhang $\mathrm{HJ}(2007)$

Zhang ZJ (2009)

Zhang ZL (2009)

Zhou L (2014)

$\begin{array}{rrrrr}5 & 11 & 1 & 19 & 2.7 \%\end{array}$

$6.50[2.10,20.10]$

$7.06[3.84,13.00]$

$1.64[1.00,2.69]$

$2.24[1.41,3.57]$

$15.00[1.45,155.31]$

$7.45[2.34,23.69]$

$4.13[1.28,13.27]$

$12.31[1.52,99.88]$

$5.37[1.56,18.49]$

$6.94[1.44,33.45]$

$4.53[1.65,12.42]$

$3.72[1.25,11.13]$

$21.79[7.78,60.99]$

$5.82[1.11,30.56]$

$13.03[5.73,29.66]$

Total $(95 \% \mathrm{Cl})$

926

$2 \quad 24 \quad 4.4 \%$

Total events $464 \quad 269$

Heterogeneity: $\mathrm{Tau}^{2}=0.47 ; \mathrm{Chi}^{2}=46.35, \mathrm{df}=15(\mathrm{P}<0.0001) ; \mathrm{I}^{2}=68 \%$

Test for overall effect: $Z=7.68(P<0.00001)$

$991 \quad 100.0 \%$

$[3.69,9.02]$

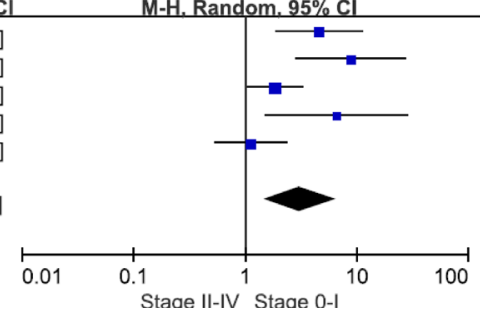

Odds Ratio

Odds Ratio

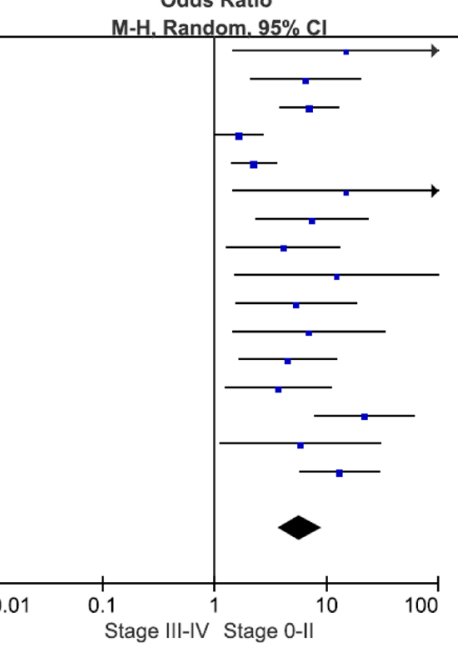




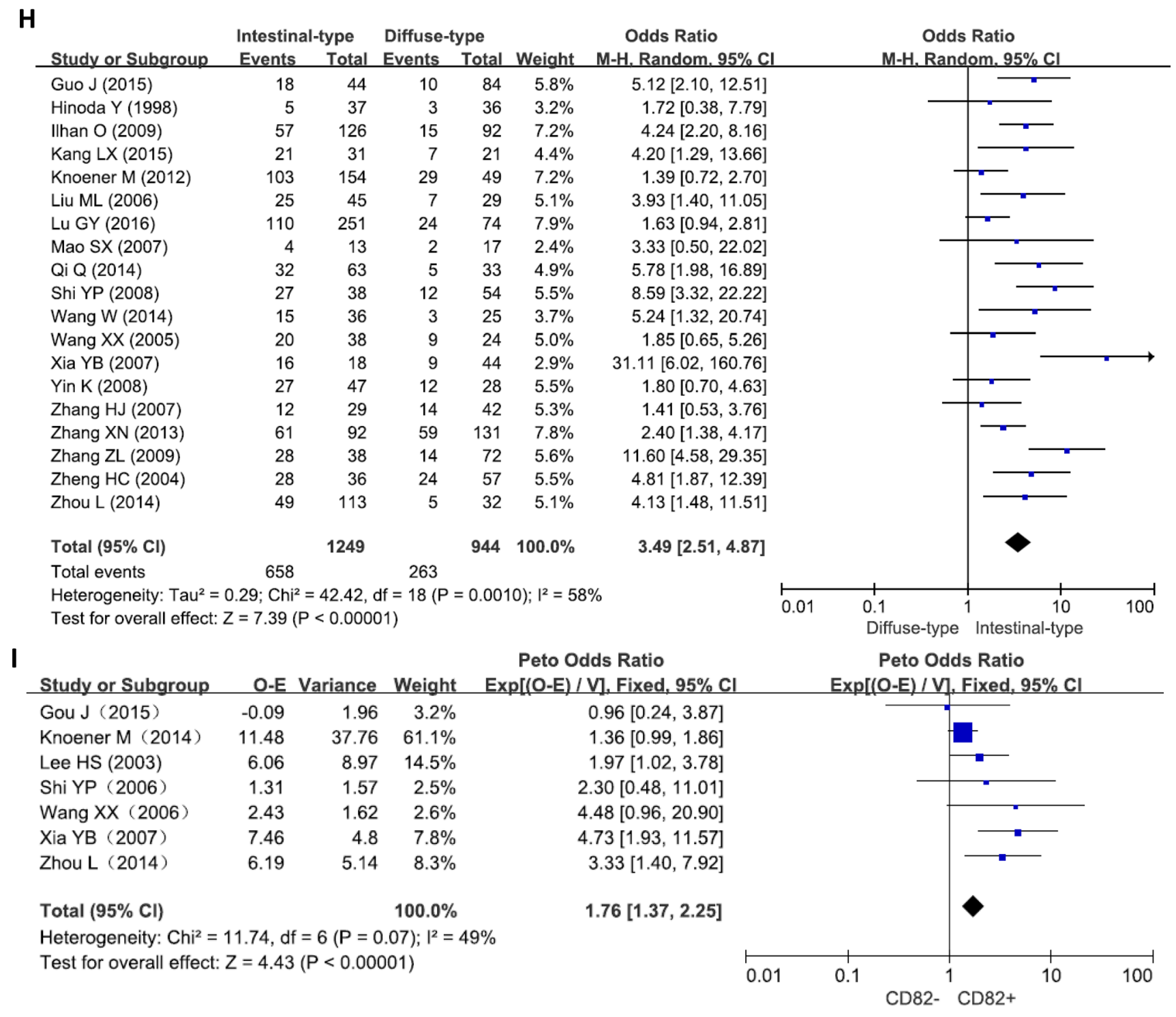

Figure 2: Forest plot for the relationship between CD82 expression and clinicopatholoiocal parameters of gastric cancer. (A) gastric carcinogenesis (cancer vs normal mucosa); (B) correlation between T staging and CD82 expression (T0-1 vs T2-4); (C) correlation between T staging and CD82 expression (T0-2 vs T3-4); (D) correlation between lymph node metastasis (LN) and CD82 expression (LN- $v s \mathrm{LN}+$ ); (E) correlation between distant metastasis (DM) and CD82expression (DM- $v s$ DM+); (F) correlation between TNM staging and CD82 expression (stage 0-I vs II-IV); (G) correlation between TNM staging and CD82 expression (stage 0-II $v s$ III-IV); (H) correlation between differentiation and CD82 (intestinal-type $v s$ diffuse-type). (I) correlation between prognosis and CD82 expression (CD82- vs CD82+).

\section{DISCUSSION}

A body of evidences indicates that CD82 inhibits migration and invasion by strengthening the cell adhesion, and weakening cellular protrusion and mobility [3843]. Reportedly, CD82 overexpression down-regulated VEGF-C expression via Src/STAT3 pathway in pancreatic cancer cell [36] and sLea/x expression via the downregulation of ST3GAL4 expression to thereby reduce the adhesion of cancer cells to blood vessels [37]. CD82 overexpression significantly inhibited migration and invasion of melanoma cells by reducing Rho-associated kinase-mediated formation of stress fiber or MMP2 activity [38]. It also inhibited polarized protrusion and retraction events by disrupting actin reorganization with deregulated Rac1, RhoA, and their effectors cofilin, and Rho kinase by perturbing the plasma membrane lipids [39]. CD82 suppressed HIF-1 $\alpha$ and VEGF expression by blocking CDCP1- enhanced Src activation in prostate cancer [40], HGF-induced migration of hepatoma cells via upregulation of Sprouty2 [41] or the inactivation of small GTP-binding proteins of the Rho family via c-Met adapter proteins [42]. Chigita et al. [43] concluded that CD82 attenuated Wnt signaling by inhibition of $\beta$-catenin nuclear translocation 


\begin{tabular}{|c|c|c|c|c|}
\hline \multirow{2}{*}{ Clinicopathological features } & \multicolumn{2}{|c|}{ Overall survival } & \multicolumn{2}{|c|}{ Progression-free survival } \\
\hline & Hazard ratio & $p$ & Hazard ratio & $p$ \\
\hline \multicolumn{5}{|l|}{ Sex } \\
\hline Female & $0.55(0.36-0.85)$ & 0.0056 & $0.53(0.35-0.81)$ & 0.0029 \\
\hline Male & $0.57(0.42-0.78)$ & $3 e-04$ & $0.6(0.44-0.81)$ & 0.00069 \\
\hline \multicolumn{5}{|l|}{$\mathrm{T}$} \\
\hline 2 & $0.53(0.34-0.83)$ & 0.0046 & $0.53(0.35-0.82)$ & 0.0032 \\
\hline 3 & $0.67(0.47-0.95)$ & 0.026 & $0.68(0.48-0.96)$ & 0.029 \\
\hline 4 & $0.57(0.25-1.32)$ & 0.18 & $0.74(0.33-1.66)$ & 0.46 \\
\hline \multicolumn{5}{|l|}{$\mathrm{N}$} \\
\hline 0 & $0.39(0.16-0.94)$ & 0.03 & $0.4(0.17-0.95)$ & 0.031 \\
\hline $1-3$ & $0.55(0.41-0.72)$ & $1.3 e^{-05}$ & $0.59(0.46-0.76)$ & $3.5 e^{-}-05$ \\
\hline 1 & $0.44(0.29-0.67)$ & $9.4 \mathrm{e}-05$ & $0.43(0.29-0.64)$ & $2.1 \mathrm{e}^{-05}$ \\
\hline 2 & $0.64(0.41-1.02)$ & 0.059 & $0.64(0.4-1.03)$ & 0.067 \\
\hline 3 & $0.44(0.24-0.8)$ & 0.0059 & $0.42(0.22-0.79)$ & 0.0054 \\
\hline \multicolumn{5}{|l|}{ M } \\
\hline 0 & $0.57(0.42-0.76)$ & 0.00011 & $0.6(0.46-0.78)$ & 0.00011 \\
\hline 1 & $0.63(0.33-1.2)$ & 0.15 & $0.64(0.33-1.26)$ & 0.2 \\
\hline \multicolumn{5}{|l|}{ TNM staging } \\
\hline I & $0.45(0.15-1.36)$ & 0.15 & $0.47(0.16-1.41)$ & 0.17 \\
\hline II & $0.5(0.26-0.98)$ & 0.04 & $0.39(0.21-0.72)$ & 0.0019 \\
\hline III & $0.58(0.39-0.86)$ & 0.006 & $0.63(0.43-0.92)$ & 0.017 \\
\hline IV & $0.69(0.46-1.05)$ & 0.083 & $1.24(0.81-1.91)$ & 0.32 \\
\hline \multicolumn{5}{|l|}{ Differentiation } \\
\hline Moderately-differentiated & $1.61(0.82-3.14)$ & 0.16 & $1.74(0.83-3.66)$ & 0.14 \\
\hline Poorly-differentiated & $1.15(0.68-1.94)$ & 0.6 & $0.84(0.53-1.33)$ & 0.45 \\
\hline \multicolumn{5}{|l|}{ Lauren's classification } \\
\hline Intestinal-type & $0.54(0.35-0.85)$ & 0.0071 & $0.6(0.42-0.87)$ & 0.0062 \\
\hline Diffuse-type & $0.57(0.41-0.81)$ & 0.0013 & $0.56(0.4-0.79)$ & 0.00092 \\
\hline Mixed-type & $0.4(0.12-1.32)$ & 0.12 & $2.24(0.69-7.24)$ & 0.17 \\
\hline \multicolumn{5}{|l|}{ Her2 positivity } \\
\hline- & $0.54(0.41-0.72)$ & $1.7 \mathrm{e}-05$ & $0.55(0.41-0.74)$ & $8.3 e-05$ \\
\hline+ & - & - & $0.67(0.43-1.04)$ & 0.074 \\
\hline \multicolumn{5}{|l|}{ Treatment } \\
\hline Surgery alone & $0.68(0.5-0.92)$ & 0.013 & $0.71(0.54-0.94)$ & 0.015 \\
\hline 5-FU-based adjuvant & $0.5(0.19-1.31)$ & 0.15 & $0.34(0.14-0.82)$ & 0.012 \\
\hline Other adjuvant & $2.06(0.84-5.04)$ & 0.11 & $0.5(0.23-1.1)$ & 0.078 \\
\hline
\end{tabular}

by down-regulation of Fzd receptor proteins, accumulation of $\beta$-catenin at the cell membrane by down-regulation of GSK-3 $\beta$ and CK $1 \alpha$, and stabilization of the E-cadherin- $\beta$ catenin complex. To investigate the clinicopathological and prognostic significances of CD82 expression, we analyzed 26 studies, which met specific inclusion criteria and had moderate to high quality according to their NOS scores.

Chai et al. [44] found that CD82 overexpression suppressed in vitro cell growth, migration, invasion and xenograft growth in oral cancer. A progressive down-regulation of CD82 was during colorectal mucosa-adenoma-the primary adenocarcinoma to the liver metastasis [45]. Zhou et al. [46] found that CD82 expression was markedly lower in cervical cancer than in the normal cervix, chronic cervicitis, or cervical intraepithelial neoplasia. Reportedly, the promoter CpGSite methylation and $\mathrm{LOH}$ of $C D 82$ contributed to its epigenetic repression $[47,48]$. Consistent with the data 
Table 3: Multivariate analysis of hazard factors of the prognosis of the patients with gastric cancer

Clinicopathological features

$\begin{array}{cc}\text { Hazard ratio }(\mathbf{9 5 \%} \mathbf{C I}) & \boldsymbol{p} \\ 1.012(0.510-2.009) & 0.973 \\ 0.742(0.331-1.665) & 0.470 \\ 0.000(0.000-4.373 \mathrm{e}-284) & 0.969 \\ 0.950(0.404-2.237) & 0.907 \\ 0.698(0.375-1.299) & 0.256 \\ 0.536(0.300-0.959) & 0.036\end{array}$

Stage T (T1-2/T3-4)

Lymph node status $(-/+)$

Distant metastasis

TNM staging (I-II/III-IV)

Lauren's classification(IT/DT)

CD82 mRNA expression

$0.536(0.300-0.959)$

come from 10 companies, the subjects of 5 countries are involved in our study, and different statistical methods are employed, CD82 expression and its correlation with clinicopathological parameters are comparatively consistent, indicating that these antibodies mainly recognize CD82 protein and its expression is independent of population or not determined by statistics. It was noted that CD82 mRNA overexpression was observed in gastric cancer according to bioinformatics analysis, in agreement with the finding about thyroid papillary carcinoma [56] and colorectal cancer [57]. The discrepancy might be due our previous work [25]. Although anti-CD82 antibodies
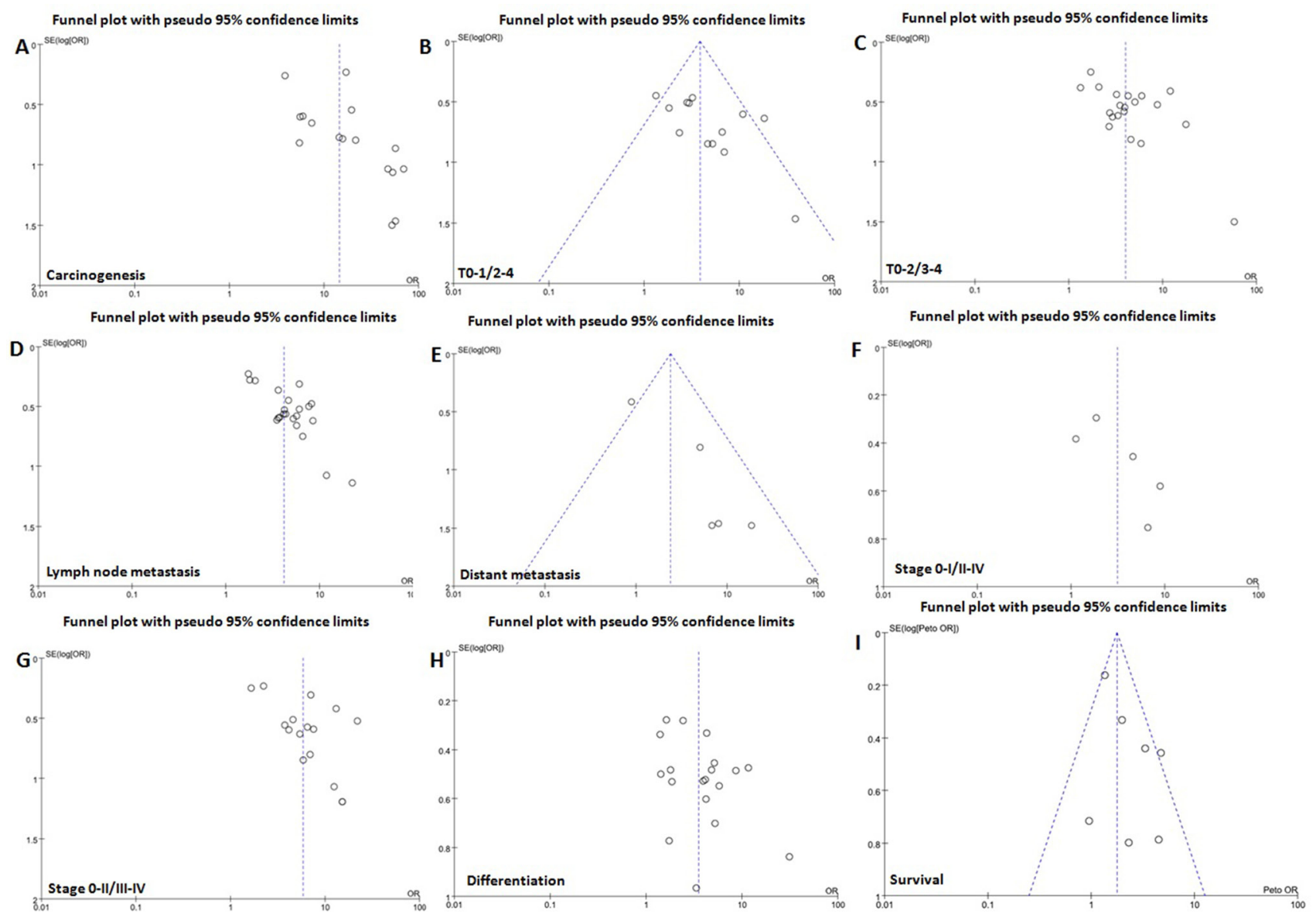

Figure 3: Funnel plot for publication bias test between CD82 expression and gastric carcinogenesis or progression. The bias was analyzed about risk degrees of CD82 expression in gastric mucosa (A) for gastric carcinogenesis. Additionally, it was tested between CD82 expression and clinicopathological features of gastric cancer, including depth of invasion (B and $\mathbf{C})$, lymph node metastasis (D), distant metastasis (E), TNM staging (F and $\mathbf{G})$, and differentiation $(\mathbf{H})$ and prognosis (I). 
to tissue specificity, long distance from mRNA to protein, and different methodologies (immunohistochemistry, transcriptomic sequencing and real-time PCR).

A body evidences showed that CD82 expression was negatively related to the poor prognosis of the patients with breast, lung, and oral cancers [58-60]. CD82 expression might be demonstrated to indicate the favorable prognosis of colorectal cancer, LSCC and melanoma as an independent factor $[50,61,38]$. Our meta-analysis showed that CD82 expression was positively linked to the better prognosis of the patients with gastric cancer. Additionally, our bioinformatics data indicated that CD82 mRNA expression was positively associated with a higher survival rates of the patient with gastric cancer, even stratified by clinicopathological features or as an independent factor. The findings can be explained by inverse correlation between CD82 expression and aggressiveness of gastric cancer.

In conclusion, CD82 expression was down-regulated from gastric carcinogenesis, but versa for its mRNA. It was negatively correlated with depth of invasion, lymph node and distant metastasis, TNM staging and dedifferentiation of gastric cancer. CD82 expression might be employed as a good potential marker for favorable prognosis of gastric cancer patients at either mRNA or protein level. Several limitations included the potential publication bias stems from published results being predominantly positive, subjective bias of survival data extracted from survival curves, and country bias of gastric cancer cases.

\section{MATERIALS AND METHODS}

\section{Identification of eligible studies and data extraction}

We performed a publication search using PubMed, Web of Science, BIOSIS and SciFinder updated on March 14, 2017. The following search terms were used: (CD82 OR Kai1) AND (gastric OR stomach) AND (cancer OR carcinoma OR adenocarcinoma). Searching was done without restriction on language or publication years.
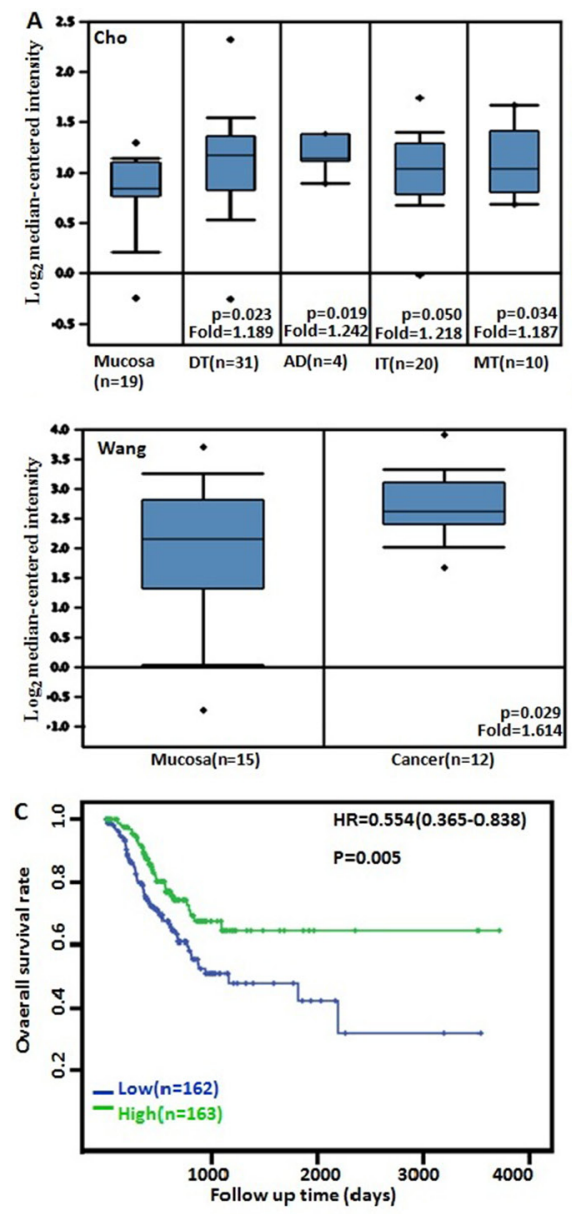
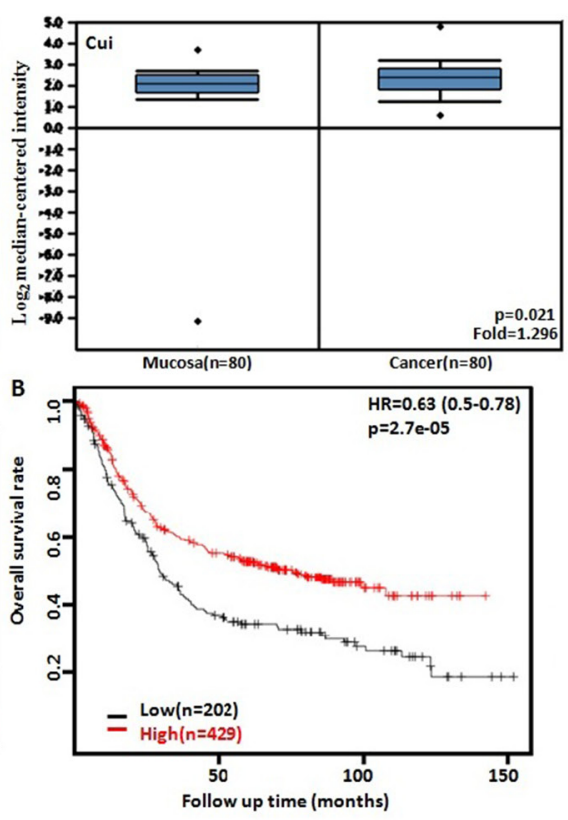
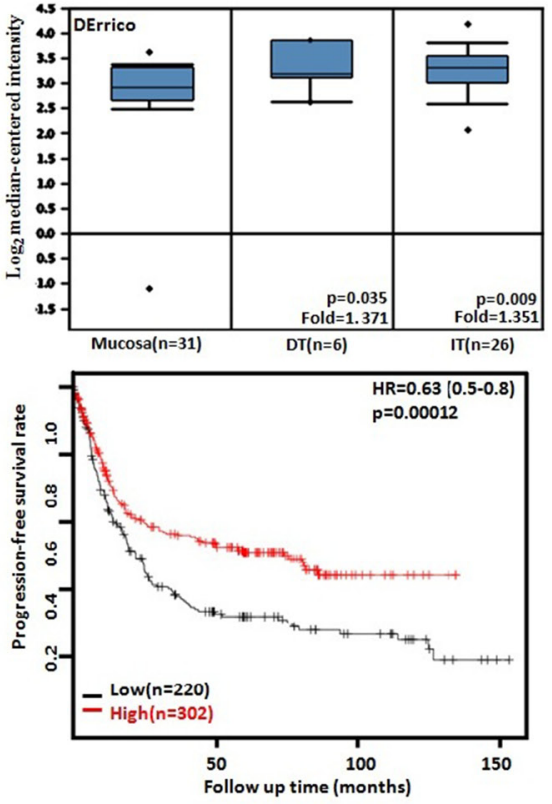

Figure 4: CD82 mRNA expression in gastric carcinogenesis and subsequent progression. Cho', Cui's, DErrico's and Wang's datasets were employed for bioinformatics analysis to analyze CD82 mRNA expression during gastric carcinogenesis. A higher CD82 mRNA expression was detectable in gastric cancer than that in normal gastric mucosa, even stratified into intestinal-, diffuse-, and mixedtype carcinomas by Lauren's classification $(\mathbf{A}, p<0.05)$. According to the data from KM plotter, $C D 82$ mRNA expression was positively related to both overall and progression-free survival rates of the patients with gastric cancer $(\mathbf{B}, p<0.05)$. It was the same from TCGA database $(\mathbf{C}, p<0.05)$. HR, hazard ratio. 
Inclusion criteria for studies included: (1) articles to observe the alteration in CD82 expression in gastric cancer by immunohistochemistry; (2) papers to compare CD82 expression with pathobiological behaviors and prognosis of gastric cancer by immunohistochemistry. Exclusion criteria included: (1) abstract, comment, review and meeting; (2) duplication of the previous publications; (3) Western blot, RT-PCR, cDNA microarray, or transcriptomic sequencing for CD82 expression; (4) lack of sufficient information.

\section{Data extraction}

Based on the inclusion criteria, two reviewers (BC Gong and HC Zheng) independently extracted information from all eligible publications. The following information was included name of first author, year of publication, country, ethnicity, antibody source, numbers of cases and controls, expression alteration, and follow-up outcome. Regarding survival analysis, we used Engauge Digitizer software to extract data from Kaplan-Meier curves and calculated the Hazard ratios (HR) and their corresponding 95\% confidence interval. Any disagreement was resolved through discussion until the two reviewers reached a consensus.

\section{Quality score assessment}

Two reviewers (BC Gong and $\mathrm{HC}$ Zheng) independently assessed the quality of the included studies according to Newcastle Ottawa Scale (NOS) (http://www. ohri.ca/programs/clinical_epidemiology/oxford.htm). The scale consists of three components related to sample selection, comparability and ascertainment of outcome.

\section{Bioinformatics analysis}

The individual gene expression level of CD82 was analyzed using Oncomine (www. oncomine.org), a cancer microarray database and web-based data mining platform for a new discovery from genome-wide expression analyses. We compared the differences in CD82 mRNA level between gastric normal tissue and cancer. All data were log-transformed, median centered per array, and standard deviation normalized to one per array. The expression (RNA-seqV2) and clinicopathological data of 392 gastric cancer patients were downloaded from the Cancer Genome Atlas (TCGA) database by TCGAassembler in $\mathrm{R}$ software. We integrated the raw data, analyzed CD82 mRNA expression in gastric cancer, and compared it with clinicopathological and prognostic data of the patients with gastric cancer. Additionally, the prognostic significance of CD82 mRNA was also analyzed using Kaplan-Meier plotter (http://kmplot.com).

\section{Statistics analysis}

HWE was evaluated using Chi-square test in control groups of each study. Strength of association between CD82 expression and cancer risk was assessed by odds ratios with $95 \%$ confidence intervals. Statistical significance of the pooled OR was determined by $Z$ test. If there was no significant heterogeneity, the fixed effect model (Mantel-Haenszel method) would be employed. Otherwise, the random effect model (DerSimonian and Laird method) would be used excluding prognostic analysis. Heterogeneity effect was then quantified by $\mathrm{I}^{2}$ test, which was subdivided into low, moderate and high degrees of heterogeneity according to the cut-off values of $25 \%, 50 \%$ and $75 \%$ respectively. Publication bias was evaluated by funnel plot and quantified by Begg's test and Egger's test to assess funnel plot asymmetry. Metaanalyses were performed with Revman software 5.3 and data from TCGA database was dealt with SPSS 10.0 software using student $t$ test. Kaplan-Meier survival plots were generated and comparisons between survival curves were made with the log-rank statistic. Cox's proportional hazards model was employed for multivariate analysis. Two-sided $p<0.05$ was considered as statistically significant.

\section{CONFLICTS OF INTEREST}

The authors have declared that no competing interests exist.

\section{FUNDING}

This study was supported by Liaoning BaiQianWan Talents Program, Award for Liaoning Distinguished Professor, a Key Scientific and Technological Project of Liaoning Province (2015408001) and National Natural Scientific Foundation of China (81472544; 81672700).

\section{REFERENCES}

1. Feng J, Huang C, Wren JD, Wang DW, Yan J, Zhang J, Sun Y, Han X, Zhang XA. Tetraspanin CD82: a suppressor of solid tumors and a modulator of membrane heterogeneity. Cancer Metastasis Rev. 2015; 34:619-633.

2. Zhang J, Wu T, Zhan S, Qiao N, Zhang X, Zhu Y, Yang N, Sun Y, Zhang XA, Bleich D, Han X. TIMP-1 and CD82, a promising combined evaluation marker for PDAC. Oncotarget. 2017; 8:6496-6512. https://doi.org/10.18632/ oncotarget. 14133 .

3. Lee J, Byun HJ, Lee MS, Jin YJ, Jeoung D, Kim YM, Lee H. The metastasis suppressor CD82/KAI1 inhibits fibronectin adhesion-induced epithelial-to-mesenchymal transition in prostate cancer cells by repressing the associated integrin signaling. Oncotarget. 2017; 8:1641-1654. https://doi. org/10.18632/oncotarget.13767.

4. Zhang P, Feng S, Liu G, Wang H, Fu A, Zhu H, Ren Q, Wang B, Xu X, Bai H, Dong C. CD82 suppresses CD44 alternative splicing-dependent melanoma metastasis 
by mediating U2AF2 ubiquitination and degradation. Oncogene. 2016; 35:5056-5069.

5. Abe M, Sugiura T, Takahashi M, Ishii K, Shimoda M, Shirasuna K. A novel function of CD82/KAI-1 on E-cadherin-mediated homophilic cellular adhesion of cancer cells. Cancer Lett. 2008; 266:163-170.

6. Odintsova E, van Niel G, Conjeaud H, Raposo G, Iwamoto R, Mekada E, Berditchevski F. Metastasis suppressor tetraspanin CD82/KAI1 regulates ubiquitylation of epidermal growth factor receptor. J Biol Chem. 2013; 288:26323-26334.

7. Odintsova E, Voortman J, Gilbert E, Berditchevski F. Tetraspanin CD82 regulates compartmentalisation and ligand-induced dimerization of EGFR. J Cell Sci. 2003; 116:4557- 4566 .

8. Risinger JI, Custer M, Feigenbaum L, Simpson RM, Hoover SB, Webster JD, Chandramouli GV, Tessarollo L, Barrett JC. Normal viability of Kai1/Cd82 deficient mice. Mol Carcinog. 2014; 53:610-624.

9. Guo J, Fan KX, Xie LI, Xiao JJ, Chen K, Hui LN, Xu ZF. Effect and prognostic significance of the KAI1 gene in human gastric carcinoma. Oncol Lett. 2015; 10:2035- 2042.

10. Zhang QH, Yao YL, Wu XY, Wu JH, Gu T, Chen L, Gu JH, Liu Y, Xu L. Anti-miR-362- 3p inhibits migration and invasion of human gastric cancer cells by Its Target CD82. Dig Dis Sci. 2015; 60:1967-1976.

11. Kang LX, Zheng H, Wang WJ, Feng YL. Expression and significance of KAI1/CD82, E-cadherin and integrin $\alpha v \beta 3$ proteins in gastric carcinoma. Mod Prev Med. 2015; 42:3939-3941.

12. Liu ML, Liu B, Xing CP, Chen YW. Expression of KAI1, nm23 and p53 in gastric carcinoma and their clinical significance. Shijie Huaren Xiaohua Zazhi. 2006; 14:491- 496.

13. Lu GY, Zhou L, Zhang X, Zhu B, Wu S, Song W, Gong X, Wang D, Tao Y. The expression of metastasis-associated in colon cancer-1 and KAI1 in gastric adenocarcinoma and their clinical significance. World J Surg Oncol. 2016; 14:276.

14. Mao SX, Wang ML, Zhu PX. The expression and clinical significance of KAI1 protein in gastric cancer. Shiyong Zhongxiyi Jiehe Linchuang. 2007; 7:3-5.

15. Qi Q, Wu SW, Cheng ZN, Guo F. Expression and significance of KAI1/CD82 and Gli1 in gastric adenocarcinoma. Chin J Histochem Cytochem. 2014; 23:282-285.

16. Shi YP, Wei XG, Zhang XL. Relationship between expression of KAI1 and CD44v6 in gastric carcinoma and survival. Linchuang Xiaohuabing Zazhi. 2008; 20:157-159.

17. Wang W, Xie JB, Yang TB, Lu HS, Zhang J. Expression and significance of KAI1 and CD44v6 in gastric carcinoma. Prac J Cancer. 2014; 29:498-500.

18. Wang XX, Feng YZ, Zhou JY, Guo XK, Liu YL, Li Y, Zhang YS. Expression and significance of KAI1/CD82 protein in gastric adenocarcinoma. Prac J Cancer. 2005; 20:484-486.

19. Wei B, Wang Q, Chen ZQ, He LJ, Zhang JD. The expression and clinical significance of KAI1 and beta-catenin in gastric cancer tissues. Chin J Gen Surg. 2008; 17:1021-1024.
20. Xia YB, Zhang F, Shi LH, Xu GX, Zhao GH. An analysis of CD82/KAI1 expression in 62 cases with gastric cancer. Zhongguo Zhongliu. 2007; 16:728-731.

21. Yin K, Luo CS, Wang MH. Expression of KAI1 and E-cadherin in 75 cases with gastric cancer. J Oncol. 2008; 14:394-395.

22. Zhang HJ, Yang GF, Liu H, Gong LL, Xiong YY. KAI1 and MMP-9 expression and microvascular density in gastric carcinoma and their relation with invasion and metastasis. Med J Wuhan Univ. 2007; 28:479-482.

23. Zhang ZJ, Ding RL, Han SL, Zhu GB. The expression and clinical significance of KAI1/CD82 expression in gastric cancer. J Surg Concept Pract. 2009; 14:563-565.

24. Zhang ZL, Fan KX, Lu YS. The expression of KAI1 protein and its clinicopathological significance in gastric carcinoma. Zhongliu Yufang Yu Fangzhi. 2009; 22:13-14.

25. Zheng HC, Wang MC, Li JY, Yang XF, Sun JM, Xin Y. Expression of CD82and kail and their clinicopathological significance in carcinogenesis and progression of gastric cancer. Chin Med Sci J. 2004; 19:193-198.

26. Zhou L, Wu SW, Yu L, Song WQ, Cheng ZN, Wang DN. [The expression of KAI1 in gastric adenocarcinoma and relationship with angiogenesis/lymphangiogenesis]. [Article in Chinese]. Sichuan Da Xue Xue Bao Yi Xue Ban. 2014; 45:43-48.

27. Knoener M, Krech T, Puls F, Lehmann U, Kreipe H, Christgen M. Limited value of KAI1/CD82 protein expression as a prognostic marker in human gastric cancer. Dis Markers. 2012; 32:337-342.

28. Ilhan O, Celik SY, Han U, Onal B. Use of KAI-1 as a prognostic factor in gastric carcinoma. Eur J Gastroenterol Hepatol. 2009; 21:1369-1372.

29. Cheng HM, Wang SQ, Yu ZM, Tang CB, Chen WH, Li LF. The expression and clinical significance of CD82, annexin II and surviving in gastric carcinoma. Acta Academiae Med Xuzhou. 2005; 25:452-455.

30. Ji RY, Zhao YF, Shu XM, Wang J, Lin B, Feng ZQ. Expression and clinical significance of KAI1/CD82 and MRP1/CD9 in gastric cancer. Jiangsu Med. 2012; 38:1640-1641.

31. Xu FY, Li N, Cai J, Zhang YM, Tang B, Niu YY, Peng ZH, Chen WS. Expressions of GRP78 and KAI1 in human gastric carcinoma tissue and their clinical significance. Acta Acad Med Milt Tert. 2010; 32:688-691.

32. Tan L, Meng XJ, Ma CX. Study the relation of the expression of KAI1 with gastric carcinoma. Henan Med Res. 2005; 14:240-241.

33. Zhang XN, Ji RY, Shi EY, Li XN, Liu HY, Dai CP, Ji ND. Expression and clinical significance of KAI1/CD82 in gastric cancer. Jiangsu Med J. 2013; 39:2268-2270.

34. Lee HS, Lee HK, Kim HS, Yang HK, Kim WH. Tumor suppressor gene expression correlates with gastric cancer prognosis. J Pathol. 2003; 200:39-46.

35. Hinoda Y, Adachi Y, Takaoka A, Mitsuuchi H, Satoh Y, Itoh F, Kondoh Y, Imai K. Decreased expression of the metastasis suppressor gene KAI1 in gastric cancer. Cancer Lett. 1998; 129:229-234. 
36. Liu X, Guo X, Li H, Chen J, Qi X. Src/STAT3 signaling pathways are involved in KAI1-induced downregulation of VEGF-C expression in pancreatic cancer. Mol Med Rep. 2016; 13:4774-4778.

37. Yoshihama N, Yamaguchi K, Chigita S, Mine M, Abe M, Ishii K, Kobayashi Y, Akimoto N, Mori Y, Sugiura T. A novel function of CD82/KAI1 in sialyl lewis antigenmediated adhesion of cancer cells: evidence for an antimetastasis effect by down-regulation of sialyl lewis antigens. PLoS One. 2015;10:e0124743

38. Tang Y, Cheng Y, Martinka M, Ong CJ, Li G. Prognostic significance of KAI1/CD82 in human melanoma and its role in cell migration and invasion through the regulation of ING4. Carcinogenesis. 2014; 35:86-95.

39. Liu WM, Zhang F, Moshiach S, Zhou B, Huang C, Srinivasan K, Khurana S, Zheng Y, Lahti JM, Zhang XA. Tetraspanin CD82 inhibits protrusion and retraction in cell movement by attenuating the plasma membrane-dependent actin organization. PLoS One. 2012; 7:e51797.

40. Park JJ, Jin YB, Lee YJ, Lee JS, Lee YS, Ko YG, Lee M. KAI1 suppresses HIF-1 $\alpha$ and VEGF expression by blocking CDCP1-enhanced Src activation in prostate cancer. BMC Cancer. 2012; 12:81.

41. Mu Z, Wang H, Zhang J, Li Q, Wang L, Guo X. KAI1/CD82 suppresses hepatocyte growth factor-induced migration of hepatoma cells via upregulation of Sprouty2. Sci China C Life Sci. 2008; 51:648-654.

42. Takahashi M, Sugiura T, Abe M, Ishii K, Shirasuna K. Regulation of c-Met signaling by the tetraspanin KAI-1/ CD82 affects cancer cell migration. Int J Cancer. 2007; 121:1919- 1929.

43. Chigita S, Sugiura T, Abe M, Kobayashi Y, Shimoda M, Onoda M, Shirasuna K. CD82 inhibits canonical Wnt signalling by controlling the cellular distribution of $\beta$-catenin in carcinoma cells.Int J Oncol. 2012; 41:2021-2028.

44. Chai J, Du L, Ju J, Ma C, Shen Z, Yang X, Liang L, Ni Q, Sun M. Overexpression of KAI1/CD82 suppresses in vitro cell growth, migration, invasion and xenograft growth in oral cancer. Mol Med Rep. 2017; 15:1527-1532.

45. Lombardi DP, Geradts J, Foley JF, Chiao C, Lamb PW, Barrett JC. Loss of KAI1 expression in the progression of colorectal cancer. Cancer Res. 1999; 59:5724-5731.

46. Zhou XL, Wang M. Expression levels of survivin, Bcl-2, and KAI1 proteins in cervical cancer and their correlation with metastasis. Genet Mol Res. 2015; 14:17059-17067.

47. Lee J, Lee MS, Jeoung DI, Kim YM, Lee H. Promoter CpGSite methylation of the KAI1 metastasis suppressor gene contributes to its epigenetic repression in prostate cancer. Prostate. 2017; 77:350-360.

48. Kim YI, Shin MK, Lee JW, Chung JH, Lee MH. Decreased expression of KAI1/CD82 metastasis suppressor gene is associated with loss of heterozygosity in melanoma cell lines. Oncol Rep. 2009; 21:159-164.

49. Zhang W, Zhao CG, Sun HY, Zheng WE, Chen H. Expression characteristics of KAI1 and vascular endothelial growth factor and their diagnostic value for hepatocellular carcinoma. Gut Liver. 2014; 8:536-542.

50. Yu L, Zhou L, Wu S, Gong X, Feng Z, Ma L, Zhu B, Yao N, Wang D, Dong H. Clinicopathological significance of cancer stem cells marked by CD133 and KAI1/CD82 expression in laryngeal squamous cell carcinoma. World $\mathrm{J}$ Surg Oncol. 2014; 12:118.

51. Shiwu WU, Lan Y, Wenqing S, Lei Z, Yisheng T. Expression and clinical significance of CD82/KAI1 and E-cadherin in non-small cell lung cancer. Arch Iran Med. 2012; 15:707-712.

52. Malik FA, Sanders AJ, Jones AD, Mansel RE, Jiang WG. Transcriptional and translational modulation of KAI1 expression in ductal carcinoma of the breast and the prognostic significance. Int J Mol Med. 2009; 23:273-278.

53. Liu FS, Dong JT, Chen JT, Hsieh YT, Ho ES, Hung MJ, $\mathrm{Lu} \mathrm{CH}$, Chiou LC. KAI1 metastasis suppressor protein is down-regulated during the progression of human endometrial cancer. Clin Cancer Res. 2003; 9:1393-1398.

54. Lijovic M, Somers G, Frauman AG. KAI1/CD82 protein expression in primary prostate cancer and in $\mathrm{BPH}$ associated with cancer. Cancer Detect Prev. 2002; 26:69-77.

55. Ow K, Delprado W, Fisher R, Barrett J, Yu Y, Jackson P, Russell PJ. Relationship between expression of the KAI1 metastasis suppressor and other markers of advanced bladder cancer. J Pathol. 2000; 191:39-47.

56. Scarpino S, Duranti E, Giglio S, Di Napoli A, Galafate D, Del Bufalo D, Desideri M, Socciarelli F, Stoppacciaro A, Ruco L. Papillary carcinoma of the thyroid: high expression of COX-2 and low expression of KAI-1/CD82 are associated with increased tumor invasiveness. Thyroid. 2013; 23:1127-1137.

57. Maurer CA, Graber HU, Friess H, Beyermann B, Willi D, Netzer P, Zimmermann A, Büchler MW. Reduced expression of the metastasis suppressor gene KAI1 in advanced colon cancer and its metastases. Surgery. 1999; 126:869-880.

58. Singh R, Bhatt ML, Singh SP, Kumar V, Goel MM, Mishra DP, Srivastava K, Kumar R. Expression levels of tetraspanin KAI1/CD82 in breast cancers in north indian females. Asian Pac J Cancer Prev. 2016; 17:3431-3436.

59. Wu SW, Yu L, Zhou L, Cheng ZN, Tao YS. Expression of Gal-3 and CD82/KAI1 proteins in non-small cell lung cancer and their clinical significance. Zhonghua Zhong Liu Za Zhi. 2013; 35:124-128.

60. Farhadieh RD, Smee R, Ow K, Yang JL, Russell PJ, Crouch R, Jackson P, Jacobson IV. Down-regulation of KAI1/CD82 protein expression in oral cancer correlates with reduced disease free survival and overall patient survival. Cancer Lett. 2004; 213:91-98.

61. Wu Q, Yang Y, Wu S, Li W, Zhang N, Dong X, Ou Y. Evaluation of the correlation of KAI1/CD82, CD44, MMP7 and $\beta$-catenin in the prediction of prognosis and metastasis in colorectal carcinoma. Diagn Pathol. 2015; 10:176. 